九州大学学術情報リポジトリ

Kyushu University Institutional Repository

\title{
An Overview of Thermal Comfort for Operators in Tractor Cabin
}

Riaz, Mahmood

Department of Agricultural Engineering, Bahauddin Zakariya University

Muhammad H. Mahmood

Department of Agricultural Engineering, Bahauddin Zakariya University

https://doi.org/10.5109/4739238

出版情報: Proceedings of International Exchange and Innovation Conference on Engineering \& Sciences (IEICES). 7, pp. 302-308，2021-10-21. 九州大学大学院総合理工学府 バージョン:

権利関係 : 


\title{
An Overview of Thermal Comfort for Operators in Tractor Cabin
}

\author{
Mahmood Riaz ${ }^{1,2}$, Muhammad H. Mahmood ${ }^{1 *}$ \\ ${ }^{1}$ Department of Agricultural Engineering, Bahauddin Zakariya University, Multan 60800, Pakistan. \\ ${ }^{2}$ Agricultural Mechanization Research Institute, Multan 60800, Pakistan. \\ *Corresponding author email: hamidmahmood@bzu.edu.pk
}

\begin{abstract}
Thermal comfort is of prime concern when it comes to tractor operator working efficiency. A comprehensive study is presented regarding issues dealing with attaining thermal comfort inside tractor cabin. Achieving thermal comfort deals not only with the condition of the tractor operator but also the immediate environment surrounding him. Several measureable factors influencing the thermal comfort inside vehicles such as, air temperature, relative humidity, mean radiant temperature, air velocity are discussed. Studies reveal human factors such as personal activity level and clothing insulation also play a vital role in determining thermal comfort. Fanger's model for numerical calculation was found to be most commonly used method of psychological human response. Whereas, physical and digital CFD manikins based on Berkeley's model are widely used and accepted nowadays for physiological human response.
\end{abstract}

Keywords: thermal comfort; tractor; operator; cabin

\section{INTRODUCTION}

Attaining thermal comfort inside vehicles has been a prime focus of automobile developers throughout history $[1,2]$. Lack of thermal comfort can adversely affect the ability of driver to focus and stay concentrated[3]. Achieving thermal comfort through air conditioning costs billions of dollars annually i.e. 26 billion liters of fuel is consumed annually in US alone to cool passenger vehicles [4]. Thermal comfort not only enhances human performance efficiency but yields benefits from livestock as well [5]

There are several ISO standards which are developed for thermal comfort of automobiles. ISO 7730: 1994 [6] and ANSI/ASHRAE 55-2004 [7] are standards dealing with thermal comfort for vehicle operators. Thermal comfort is " condition of mind which expresses satisfaction with thermal environment" as defined by Fanger [8,9]. Human thermal comfort is mainly influenced by air temperature, humidity, main radiant temperature, relative air velocity, activity level and the insulation value of the clothing $[6,10]$. Previous studies relating to thermal comfort either deal with thermal comfort affected by vehicle's inside environment or to the human response to its surrounding [11-14]. Most of these studies are related to cars and a very few deal with thermal comfort in tractors. Although a solution in the form of evaporative cooled vests for the local farm workers has been proposed [15], its assessment based on thermal comfort is yet to be made. The main objective of this paper is to provide a basis for understanding the overall factors affecting thermal comfort inside tractor cabin. It shall also encompass different methods and models studied over time to help achieve thermal comfort inside tractor cabin. Finally, the most suitable thermal comfort model for testing local tractor cabin cooling performance shall be selected.

\section{FACTORS AFFECTING THERMAL COMFORT INSIDE TRACTOR CABIN}

Thermal comfort inside tractor cabin is affected by several factors. The ever-changing surrounding environment of tractor makes achieving thermal comfort even more challenging. The unsteady, non-uniform conditions around tractor demand consideration of several other factors. However, thermal comfort of human body inside any vehicle is directly related to environmental factors as well [16]. All factors either measureable or personal should be considered to help achieve better thermal comfort [17]. Several measureable factors for determining thermal comfort are air temperature, air velocity, radiant temperature and relative humidity. Whereas, personal activity level and clothing insulation are considered as human experience based factors [6]. Solar exposure directly effects thermal comfort inside enclosed cabins [18]. Tractor operators in Pakistan are severely exposed to sunlight during summer season. The tractor operator inside cabin partially receives heat flux transmitted through glass and surrounding surfaces. The more the body is exposed to the solar radiation the more the body absorbs [19]. Heat transfers in body through conduction, convection, radiation or by person's activity [20]. The interaction of these heat transfer modes introduce sudden variations in the vehicle cabin environment when exposed to sun which makes it a complicated problem to solve[21]. Attaining thermal comfort inside tractor cabin can be much more complex as compared to inside a room due to the factors like, ever changing position of the tractor with respect to sun; the complex shape of the tractor cabin, rapid sudden microclimatic changes inside cabin, fixed position of operator inside tractor, large portion of cabin is enclosed with glass and relatively larger glazing area inside cabin[22]. Thermal comfort for tractors is also a prime concern for engineers in terms of improving efficiency of energy resources in vehicles [23,24]. To attain thermal comfort inside vehicle cabin engineers need to design more effective ventilation and air conditioning systems [25]. Eighteen factors have been presented by Nan et. al which effect the thermal comfort of occupants including outdoor dust particles, the rate at which the foreign elements could be removed [26]. This study also concludes that most studies focus on air temperature due to ease in determining it, however the direct influence of other factors on air temperature is generally ignored. Indoor pollutants are also being ignored and it needs to be studied in the future studies. In case of tractor the exposure to soil particles particularly during field operations could not be escaped to a greater extent. 


\subsection{Measureable factors}

2.1.1 Air temperature: In simple words it is the temperature of the environment around human body. Air temperature should be in range of $23-28^{\circ} \mathrm{C}$ to fulfill the thermal comfort requirements [27]. A difference of $3^{\circ} \mathrm{C}$ is acceptable between head and ankle level inside vehicle [28]. Air temperature inside vehicle also depends on factors like; size of vehicle cabin, fabric used inside cabin, glazing area [29]. An outdoor air temperature of $34^{\circ} \mathrm{C}$ can cause an indoor temperature of $72^{\circ} \mathrm{C}$ in summer

2.1.2 Relative Humidity (RH): It is the amount of water in the air relative to the water vapor quantity that the air could hold [28]. Thermal comfort is influenced only when RH is outside the range of $30-70 \%$. Above $70 \%$ it restricts evaporation from human skin which leaves the vehicle occupants with discomfort. Below 30\% RH inside vehicle creates a dry sensation among operator resulting adverse effect on mucous membranes [29].

2.1.3 Mean radiant temperature: It is the consistent temperature of an virtual dark compound which would result in same heat loss by heat emission from the person as the actual cage [29]. The mean radiant temperature can be calculated if the following is known; the surface around the vehicle operator, temperature of the operator and for every surface around operator inside cabin. Detailed measurement methods can be found in [30,31].

2.1.4 Air velocity: The mean speed of the air which a body faces is known as air velocity [32]. A person's head, neck and feet are sensitive to air movement. An air velocity too high or low around these areas introduces thermal discomfort which makes it critical to have the right air flow where required [33]. The air-conditioned air is circulated inside vehicle cabin through adjustable vents resulting in removal of heat from the human body. The distribution of local air and air temperature defines the airflow inside vehicle cabin[34]. Air flow velocity inside vehicle cabin ranges from $0.1-0.4 \mathrm{~m} / \mathrm{s}$ [28]. The aim of suitable combination of local air velocity and temperature is to ensure comfortable skin temperature, airflow circulation around operator, avoiding eye irritation and supply ample clean air for comfortable breathing [35]. The findings of the study reveal that to remove the heat effectively from the body within a cabin higher air velocities are beneficial as long as they remain within the permissible limits [35]. It was also suggested to work on the local sensation aiming at the operator's seat and the effect of solar radiation for further improvement in the cabin's environment.

\subsection{Human factors for thermal comfort inside vehicle cabin}

2.2.1 Personal activity level: Human need energy to work and maintain a body temperature around $36.5^{\circ} \mathrm{C}$. A higher surrounding temperature induces evaporation of perspiration to maintain body temperature. Too little or higher heat production inside body leads to thermal discomfort[36,37]. Moreover, human activity level has a strong correlation with thermal sensation, comfort and temperature preferences [38]. Metabolic rates for different human activity show that the lying down results in the consumption of $0.8-47 \mathrm{~W} / \mathrm{m}^{2}$. Whereas the sitting posture results in the estimated metabolic rate of 1.0-58
$\mathrm{W} / \mathrm{m}^{2}$ of the metabolic rate. This information is useful in determining the heat produced by the activity of the person sitting in the vehicle [39].

2.2.2 Clothing Insulation: Clothing keeps a heat balance between skin and its surrounding [40]. Type of clothing fabric helps or restricts transfer of perspiration from human skin, thus effecting thermal comfort [40]. The clothing insulation is measured in Clo [41]. Clothes worn in the indoor are usually light and can measure upto 0.5 Clo. Whereas summer clothing in the indoor can range upto 0.8-1.2 Clo. Winter clothing can have a relatively higher insulation thermal range i.e. upto 2-3 Clo [39].Clothing insulation is generally effected by; air speed (higher air speed leads to decreased clothing insulation), physical activity and human perspiration (unsuitable clothing insulation may not facilitate thermal comfort) [28].

\subsection{Cabin Design Factors Affecting Thermal Comfort}

The geometry and design of vehicle cabin is critical for determining the thermal load. Cabin design factors affecting thermal load include $\mathrm{A} / \mathrm{C}$ size and outlet location, windshield angle, body vent location, ventilation and seat location[42]. The solar load in compartment is influenced by glass properties and solar incidence angle. The absorptivity, transmissivity and reflectivity of glass is also influenced by incident angle of the sun.

\section{METHODS FOR ASSESSMENT OF THERMAL COMFORT}

The thermal comfort inside vehicle is determined by methods presented in EN ISO 14505 [43] and American ASHRAE-55[44]. EN ISO 7730 shows Predicted Mean Value (PMV) and Predicted Percentage of Dissatisfied (PPD) which were explained by Fanger [45]. Fanger's model is based on person's own sensation which is described as per ASHRAE scale with seven values ranging from -3 to 3 with 0 value showing the neutral comfortable conditions for the occupant [44]. The relation used to evaluate the PMV index is presented [45]:

$$
\begin{aligned}
P M V=0.03 e^{0.303} & +0.028)\{(M-W) \\
& -3.05\left[5.73-0.007(M-W)-p_{a}\right] \\
& -0.42[(M-W)-58.15] \\
& -0.0173 M\left(5.87-p_{a}\right) \\
& -0.0014 M\left(34-t_{a}\right) \\
& -396.10^{-8} f_{c l}\left[\left(t_{c l}+273\right)\right. \\
& \left.\left.-\left(t_{m r}+273\right)^{4}\right]-f_{c l} h_{c}\left(t_{c l}-t_{a}\right)\right\}
\end{aligned}
$$

The PPD index [44] is expressed by equation:

$$
\begin{gathered}
\mathrm{PPD}= \\
\left.\left.0.2179 \mathrm{MV}^{2}\right)\right]
\end{gathered}
$$

The EN ISO 14505 standard "Evaluation of thermal environments in Vehicles" is structured into three parts. All these three methods have been studied by researchers to assess thermal comfort. Some researchers studied via human response based surveys, other choose to assess environment via sensors. Majority of studies choose to analyze air temperature especially at head and ankle level This helps understand how quickly air temperature changes and to what extent the cabin environment is 
homogenized. However, other key factors like air velocity and solar radiation inside cabin cannot to ignored for assessing thermal comfort [46].

A dedication probe can be used to measure relative humidity at any point [46]. The air temperature inside cabin was measured by [47] at several points with thermocouples to check the thermal homogenization and time required. Skin temperature was monitored at nine different locations. The data obtained was evaluated on a seven point scale. Correlation between skin temperature and thermal sensation was found.

It was noted that the sensor's recorded higher values (atleast $2^{\circ} \mathrm{C}$ ) if they were placed in direct sun light as compared to being under shaded regions [48].

The effect of $40 \%$ solar radiation protection film on all windows except windscreen was studied via questionnaire survey [49]. A solar thermal radiation reduced up to $20 \%$ and up to $18 \%$ fuel saving was reported.

Another technique to measure thermal comfort is by taking thermal infrared images of the face of the person under complete thermal comfort and then compare them with face under different conditions [50]. Results obtained when compared with thermocouple data successfully predicted thermal conditions. This method was expensive and can be used for in depth studies.

Thermal comfort indicators were studied via 24 thermocouples[19], a vane anemometer and wind direction locator at different locations within the vehicle cabin. Data regarding air temperature, radiant temperature, humidity and air velocity helped assessing thermal comfort [49], [50]. Thermocouples and anemometer can also be installed on a manikin to study thermal comfort [51].

Fanger's equation were used on 16 tractor operator's to predict thermal comfort by Kaufman [13]. The methodology was successful in determining thermal comfort but resulted in conclusion that thermal comfort cannot be achieved just by controlling temperature. The sixteen male subjects, who remained in the experimental cab for two hours, were allowed to control the temperature until they feel thermal comfort. The result in this study demonstrated the practical application of Fanger's model.

Several studies used visualization techniques instead of measuring variables. This enables one to study air velocity and temperature data at the same time. This methodology helped study the effect of inlet air velocity with ventilation on a two dimensional one-fifth scale model [52]. Laser Doppler anemometry system was also used to measure the flow of air inside vehicle cabin [53].

Particle streak velocimetry (PSV) method was used in 1992 to measure the isothermal flow field in a car and a quarter scale prototype using two manikins. This study was used to study the effect of vehicle occupants on the air flow map. This helped in better air conditioning performance with enhanced thermal comfort [54].

Ruzic D [57] used STAR-CCM+ CFD software to simulate thermal conditions inside a virtual tractor cab on a virtual manikin. The required thermal data was input in the software to gain results showing that the maximum heat flux was observed at the back of the operator inside tractor cabin.

Almost half of the heat load inside vehicle is due to solar radiation [10]. The compressor power can be reduced upto 740w just by the replacement of ordinary glass with infrared reflection glass [58]. Determining linear radiation heat transfer coefficient, proposed by ASHRAE, helps understand thermal heat transfer between two surfaces [57].

Human thermal interaction with its surrounding yields physiological and psychological response [58]. The main feature of the thermal model comprises thermal energy transfer with its surrounding, the response of the human body to that transfer and how one feels about that heat also known as thermal perception [59]. To counter expensive human experience based experiments, physical models and manikins were developed.

Fanger developed a model which could determine thermal comfort under constant heat load [7]. Whereas, Gagge et al. demonstrated the difference between the thermal comfort and temperature sensation in changing environment [60]. This model was able to predict mean skin temperature and core temperature along with skin blood flow and total evaporative heat loss. Stolwijk [11] used 25 nodes to determine thermal characteristics of a body. Thermal manikin was applied to study thermal comfort in a vehicle by Kohri [63].

Berkeley model can simulate vehicle cabin environment. The input data can be easily modified and is applicable to non-uniform conditions in this model [64].

Human thermal psychological model have two approaches. In first type of models environmental data and human thermal response are statistically analyzed. In second approach human physiological response to its surroundings is compare to thermal sensation responses. The factors influencing are overall heat transfer, the measure of heat transfer and the percent of heat transfer of the individual [63]. Fanger [8] and Gagge [60] models study PMV and moisture related temperature under steady state environments.

Taniguchi el al.[66,67] studied the temperature and its rate of change at the face of the vehicle occupants to develop thermal comfort model. Non uniform environments were examined using Equivalent Homogenous Temperature (EHT) with thermal manikins to devise thermal sensation in the Berkeley human thermoregulatory model [66]. The EHT was also used by a more advanced thermal comfort determining method of virtual thermal comfort engineering (VTCE) technique [67].

The psychological response was also estimated using a neural network comprising of skin temperature of different body parts in layer. The data was compared with another layer of thermal human sensation [12]

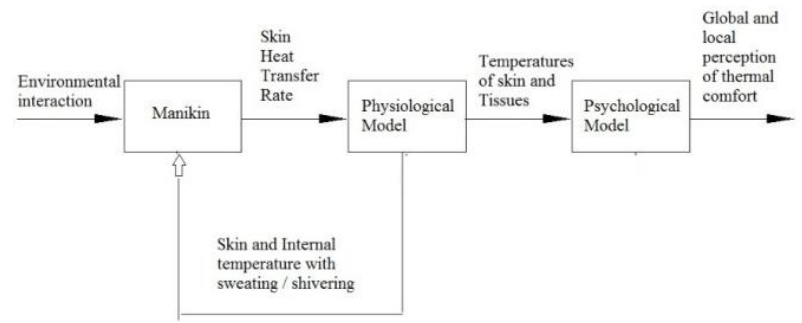

Fig. 1 Diagram for Individual thermal comfort sensation [70] 
ASHRAE seven point scale psychological method was extended to nine point scale in NREL. The scale included 'very cold' and 'very hot' thermal conditions. The model was validated using over 100 human subjects under steady state environments [69].

3.1 Thermal Manikins: Human thermal response is often subjective and several other non-environmental factors can affect human behavior. Moreover, exposing a large group of people under variable thermal conditions is always a difficult task. Advanced manikins can predict physiological and psychological responses to thermal conditions. Virtual thermal manikins are another advanced method which has a numerical approach towards thermal response. An overview by Nilsson [72] discusses thermal manikins physical and numerical development in detail.

A physical manikin which can simulate human response to thermal environment should be able to sit, have fast response to thermal changes and should be able to sense non-uniform thermal conditions. Moreover, a multi-segment manikin for easy movement, various posture with digital controls was preferred [66], [70][73]. Overtime manikins were updated to simulate physical perspiration, respiration along with instruments which can measure air temperature, air velocity, relative humidity, mean radiant temperature and clothing level[73,74]. Modern day manikins make use of computer technology and computational dynamics. An Advanced Automotive Manikin (ADAM) as shown in fig. 2 had 126 independently controlled segments with moveable joints. It was able to perspire, breath with power sources and wireless data transmission devices $[60,71]$.

CFD techniques in manikins are also used for determining thermal comfort in vehicles [75,76]. University of Berkeley along with Delphi Harrison Thermal Systems used virtual passengers to numerically predicted thermal comfort inside vehicle. The technique was called virtual thermal comfort engineering (VTCE) and it was able to predict the following; (i) effect of size of vehicle cabin (ii) solar load estimation (iii) heat load around occupants (iv) Analysis of the system's air conditioning (v) cabin thermal environment (using manikin of CFD) (vi) physiological model for core and skin temperature (vii) thermal comfort analysis with EHT concept. Figure 3 shows the schematic process of VTCE.

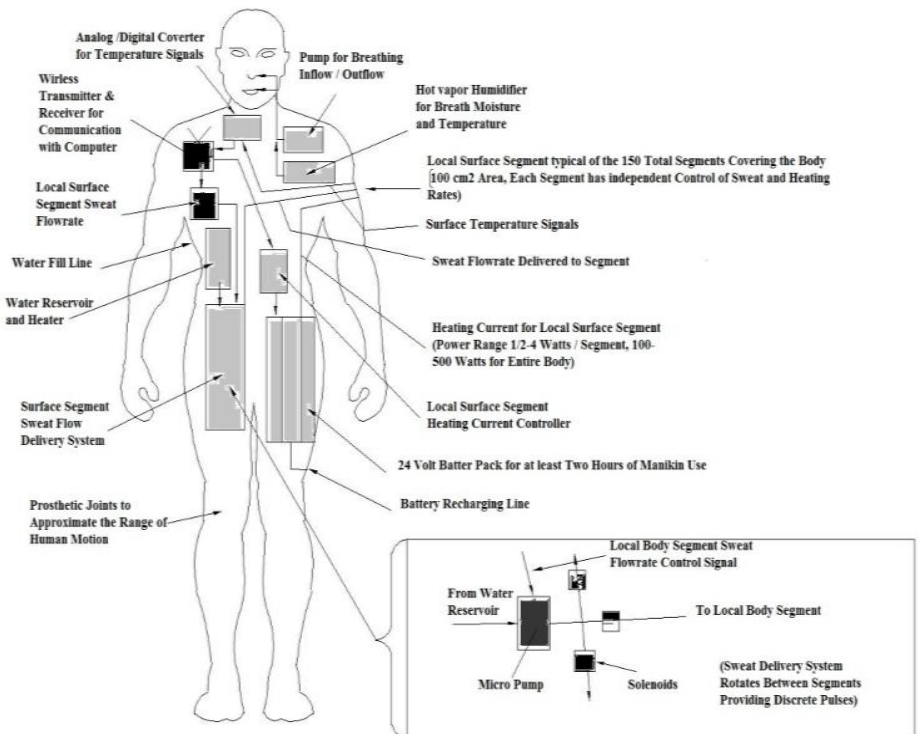

Fig.2 Detailed description of ADAM [60]

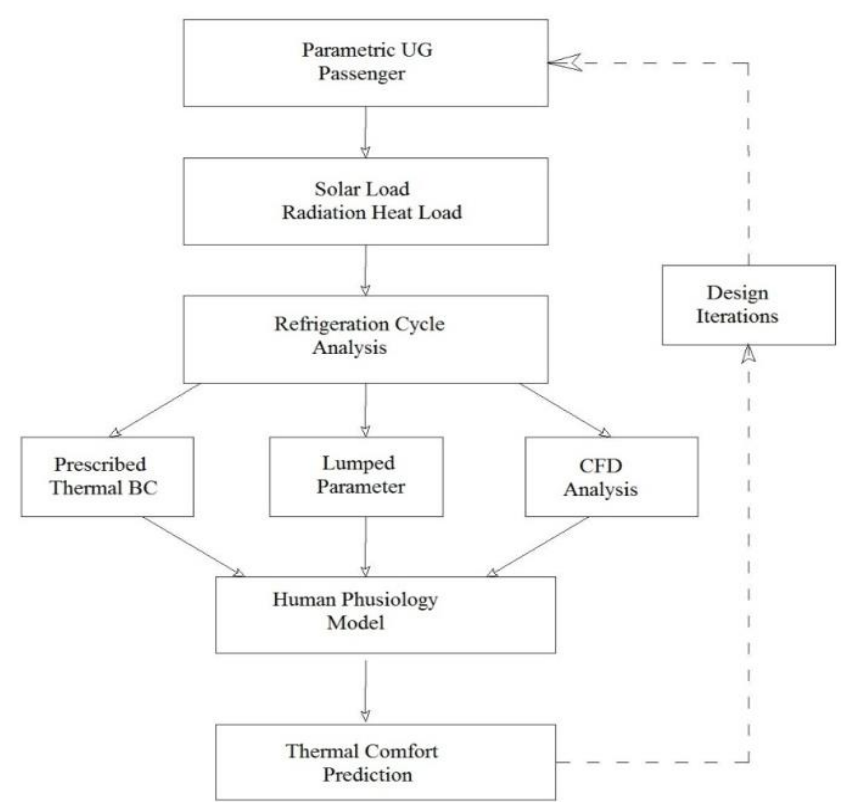

Fig.3 Schematic of Virtual Thermal comfort engineering process[70].

\section{PROPOSED MODEL FOR PREDICTING THERMAL COMFORT IN TRACTOR CABIN UNDER LOCAL CONDITION}

After going through several techniques for assessing thermal comfort the most suitable thermal model under local conditions and limited resources is presented here which was used for the development of thermal model of a car[77]. In this model for the purpose of simplification the surfaces were simplified and were considered flat. This technique was previously adopted by Khayyam et al. [78] Fayazkakhsh and Bahrami [79] and Wang [80]. In this model different heat fluxes on the vehicle cabin glass are shown in fig. 4 , whereas, the changes in the air temperature can be calculated by equation below[77].

$$
m_{\text {air }} C_{p_{\text {air }} \frac{d T a i r}{d t}}=Q_{\text {windows }}+Q_{\text {ceilling }} Q_{\text {base }}+Q_{\text {human }}
$$




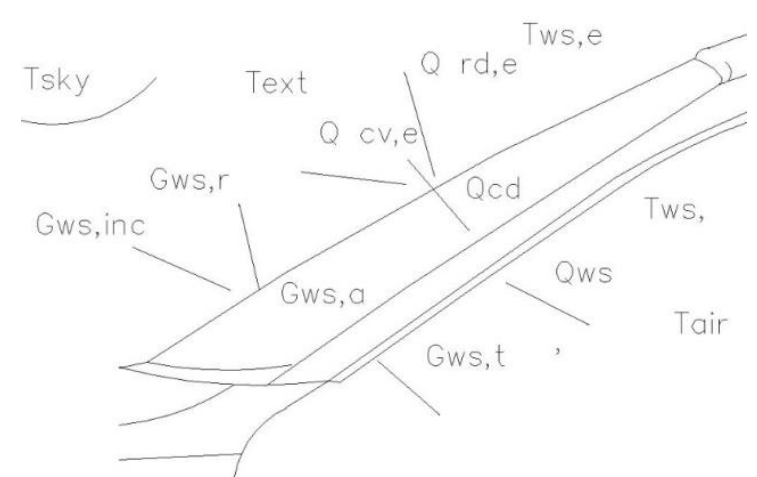

Fig.4 heat fluxes in windshield [77]

\section{CONCLUSION:}

This paper presents relevant factors which can be effectively used to assess thermal comfort inside a tractor cabin. It concludes that thermal environment of a cabin can be determined with the help of six basic thermal comfort factors. However, there are several other factors that shall be taken into account when determining the thermal comfort for tractor operator. Computational fluid dynamics (CFD) could virtually predict thermal comfort conditions inside a tractor cabin with the help of a virtual manikin. Also, psychrometric chart could be a used for determining the key factors if data regarding air temperature and relative humidity is acquired.

\section{ACKNOWLEDGEMENT:}

This work is part of Ph.D study of Mr. Mahmood Riaz. The research work has been carried out at the Department of Agricultural Engineering, Bahauddin Zakaria University, Multan, Pakistan.

\section{REFERENCES}

[1] Bhatti MS. Evolution of Automotive Heating (Riding in Comfort: Part I). ASHRAE J 1999:51-60.

[2] Bhatti MS. Evolution of Automotive Air Conditioning (Riding in Comfort: Part II). ASHRAE J 1999:44-50.

[3] Norin F, Wyon DP. Driver Vigilance - The Effects of Compartment Temperature. SAE Tech Pap 1992. https://doi.org/10.4271/920168.

[4] Rugh JP, Farrington RB, Bharathan D, Vlahinos A, Burke R, Huizenga C, et al. Predicting human thermal comfort in a transient nonuniform thermal environment. Eur J Appl Physiol 2004;92:721-7. https://doi.org/10.1007/S00421004-1125-2.

[5] Hafiz S. Ullah, Ashraf H, Bilal M, Sultan M, Shabir F, Ashraf S, et al. Evaporative Cooling Systems for Thermal Comfort of Foreign Cattle Breeds: THI Evaluation and System Feasibility. Proc Int Exch Innov Conf Eng Sci 2020;6:98103. https://doi.org/10.5109/4102473.

[6] Olesen BW, Parsons KC. Introduction to thermal comfort standards and to the proposed new version of EN ISO 7730. Energy Build., vol. 34, 2002, p. 537-48. https://doi.org/10.1016/S03787788(02)00004-X.

[7] Olesen B, Brager G. A better way to predict comfort: The new ASHRAE standard 55-2004.
ASHRAE J 2004:20-30.

[8] Fanger PO. Thermal comfort. Analysis and applications in environmental engineering. Copenhagen: Danish Technical Press; 1970.

[9] Transacions PF-A, 1967 undefined. Calculation of thermal comfort-introduction of a basic comfort equation. CiNiiAcJp n.d.

[10] Olesen, B. W., Rosendahl J. Thermal comfort in trucks. SAE Tech Pap Ser No 905050, Warrendale, PA, 1990:349-55.

[11] Shimizu S, Hara H, Asakawa F. Analysis on AirConditioning Heat Load of a Passenger Vehicle. Int J Veh Des 1983;4:292-311. https://doi.org/10.1504/IJVD.1983.061317.

[12] Stolwijk J, Mitchell J, Nadel E. Development of mathematical models of environmental physiology. 1971.

[13] Furuse K, Komoriya T. Study of passenger's comfort in non-uniform thermal environments of vehicle compartment. JSAE Rev 1997;18:411-4. https://doi.org/10.1016/S0389-4304(97)00033-7.

[14] Kaufman KR, Turnquist PK, Swanson RN. Thermal Comfort in an Air-Conditioned Tractor Cab. Trans ASAE 1979;22:694-0698. https://doi.org/10.13031/2013.35084.

[15] Maqsood A, Riaz M, Muhammad H. Mahmood, Sultan M. Study on an Evaporative Cooling Vest for Farm Workers. Proc Int Exch Innov Conf Eng Sci 2020;6:116-21. https://doi.org/10.5109/4102475.

[16] Croitoru C, Nastase I, Bode F, Meslem A, Dogeanu A. Thermal comfort models for indoor spaces and vehicles - Current capabilities and future perspectives. Renew Sustain Energy Rev 2015;44:304-18.

https://doi.org/10.1016/j.rser.2014.10.105.

[17] Haller G. Thermal comfort in rail vehicles. Rail Tec Arsenal 2006.

[18] Hodder S, Parsons K. The effects of solar radiation and black body re-radiation on thermal comfort. Ergonomics 2008;51:476-91. https://doi.org/10.1080/00140130701710986.

[19] Ruzic D, Casnji F. Thermal Interaction Between a Human Body and a Vehicle Cabin. Heat Transf Phenom Appl 2012. https://doi.org/10.5772/51860.

[20] Regnier C. Guide to setting thermal comfort criteria and minimizing energy use in delivering thermal comfort 2013. https://doi.org/doi:10.2172/1169480.

[21] Temming J. Comfort requirements for heating, ventilation and air conditioning in motor vehicles. 1980.

[22] Hodder SG, Parsons K. The effects of solar radiation on thermal comfort. Int $\mathrm{J}$ Biometeorol 2007;51:233-50.

https://doi.org/10.1007/S00484-006-0050-Y.

[23] Manojlović A V., Papić VD, Filipović SM, Jovanović VD. Fleet renewal: An approach to achieve sustainable road transport. Therm Sci 2011;15:1223-36. https://doi.org/10.2298/TSCI110504111M.

[24] Jović JJ;Đori. VD. Application of transport demand modeling in pollution estimation of a street network. Therm Sci 2009;13:229-43. 
https://doi.org/https://doi.org/10.2298/TSCI090 3229J.

[25] Gökhan, Sevilgen;Kiliç M. Investigation of transient cooling of an automobile cabin with a virtual manikin under solar radiation. Therm Sci 2013;17:297-406.

https://doi.org/10.2298/TSCI120623150S.

[26] Ma N, Aviv D, Guo H, Braham WW. Measuring the right factors: A review of variables and models for thermal comfort and indoor air quality. Renew Sustain Energy Rev 2021;135:110436.

https://doi.org/10.1016/J.RSER.2020.110436.

[27] Meslem A, Bode F, Croitoru C. Comparison of turbulence models in simulating jet flow from a cross-shaped orifice. Eur J Mech - B/Fluids 2014;44:100-20.

https://doi.org/https://doi.org/10.1016/j.euromec hflu.2013.11.006.

[28] Brasov UT, Helerea E, Musat R. Parameters and Models of the Vehicle Thermal Comfort Monitoring the electromagnetic environment View project Radu Musat Parameters and Models of the Vehicle Thermal Comfort. Acta Univ Sapientiae Electr Mech Eng 2009;1:215-26.

[29] Zhou Q. Thermal Comfort in Vehicles. University of Gavle, 2013.

[30] Höppe P. A new procedure to determine the mean radiant temperature outdoors. Wetter Unt Leb 1992;44:147-51.

[31] Spagnolo J, de Dear R. A field study of thermal comfort in outdoor and semi-outdoor environments in subtropical Sydney Australia. Build Environ 2003;38:721-38. https://doi.org/10.1016/S0360-1323(02)00209-3.

[32] ASHRAE Standard-55. Thermal environmental conditions for human occupancy. 2010.

[33] Youssef Riachi DC. A Numerical Model for Simulating Thermal Comfort Prediction in Public Transportation Buses. Int J Environ Prot Policy 2014;2:1-8. https://doi.org/10.11648/j.ijepp.20140201.11.

[34] Ruzic D, Casnji F. Thermal Interaction Between a Human Body and a Vehicle Cabin. Heat Transf. Phenom. Appl., InTech; 2012. https://doi.org/10.5772/51860.

[35] Ruzic D. Improvement of thermal comfort in a passenger car by localized air distribution. ACTA Tech Corviniensis-Bulletin Eng 2011.

[36] Parsons K. The estimation of metabolic heat for use in the assessment of thermal comfort. Proc. Conf. Mov. Therm. Comf. Stand. into 21st Century, 2001.

[37] Appah-Dankyi J, Koranteng C. An assessment of thermal comfort in a warm and humid school building at Accra, Ghana 2012.

[38] Kumar A, Singh IP, Sud SK. An approach towards development of PMV based thermal comfort smart sensor. Int J Smart Sens Intell Syst 2010;3:621-42. https://doi.org/10.21307/ijssis2017-412.

[39] Alahmer A, Omar MA, Mayyas A, Dongri S. Effect of relative humidity and temperature control on in-cabin thermal comfort state: Thermodynamic and psychometric analyses.
Appl Therm Eng 2011;31:2636-44. https://doi.org/10.1016/J.APPLTHERMALENG .2011.04.033.

[40] Li Y. The science of clothing comfort. Text Prog 2001;31:1-135. https://doi.org/10.1080/00405160108688951.

[41] Abhishek, R; Balachander R. Thermal Comfort in a Closed Space Based on Closed Loop Temperature Ccontrol. 2010.

[42] Han T, Huang L, Kelly S, Huizenga C, Hui Z. Virtual thermal comfort engineering. SAE Tech Pap 2001. https://doi.org/10.4271/2001-01-0588. [43] Rolle A, Schmandt B, Guinet C, Bengler K. Assessment of Thermal Comfort in Different Vehicle-Classes - The Suitability of ISO 145052:2006-12 2021:806-13. https://doi.org/10.1007/978-3-030-74608-7_99.

[44] ASHRAE. Standard-55. 2004.

[45] Shaw EW. Thermal Comfort: analysis and applications in environmental engineering. $\mathrm{R}$ Soc Health J 1972;92:164-164. https://doi.org/10.1177/146642407209200337.

[46] Danca P, Vartires A, Dogeanu A. An Overview of Current Methods for Thermal Comfort Assessment in Vehicle Cabin. Energy Procedia 2016;85:162-9.

https://doi.org/10.1016/J.EGYPRO.2015.12.322.

[47] Zhang W, Chen J, Lan F. Experimental study on occupant's thermal responses under the nonuniform conditions in vehicle cabin during the heating period. Chinese J Mech Eng 2014272 2014;27:331-9.

https://doi.org/10.3901/CJME.2014.02.331.

[48] Kilic M, Akyol SM. Experimental investigation of thermal comfort and air quality in an automobile cabin during the cooling period. Heat Mass Transf 2012488 2012;48:1375-84. https://doi.org/10.1007/S00231-012-0988-8.

[49] Srisilpsophon T, Tiansuwan J, Kiatsiriroat T. Effect of anti-solar glass film on heat transfer and mean radiant temperature inside cabin of airconditioned vehicle. Http://DxDoiOrg/101080/014307502007967502 2 2011;28:39-50. https://doi.org/10.1080/01430750.2007.9675022.

[50] Ghiardi GL. Occupant thermal comfort evaluation. Thermosense XXI 1999;3700:32431. https://doi.org/10.1117/12.342302.

[51] Lin C, Lelli M, Han T, Niemiec R, Hammond D. An experimental and computational study of cooling in a simplified GM-10 passenger compartment 1991.

[52] Chakroun W, Al-Fahed S. Thermal comfort analysis inside a car. Int J Energy Res 1997;21:327-40.

https://doi.org/10.1002/(SICI)1099-

$114 X(19970325) 21: 4<327::$ AID-

ER247>3.0.CO;2-E.

[53] Kataoka T, Nakamura Y. Prediction of thermal sensation based on simulation of temperature distribution in a vehicle cabin. Heat Transf Asian Res 2001;30:195-212. https://doi.org/10.1002/HTJ.1010.

[54] Komoriya T. Analysis of vehicle passenger compartment ventilation using experimental and 
numerical model. SAE Tech. Pap., 1989. https://doi.org/10.4271/890312.

[55] Klemp, k; Heinz, Herwig;Gerhard W. LDA measurements in a model of a passenger-carcabin. Laser Anemometry 1991.

[56] Ishihara Y, Shibata M, Hoshino H, Hara J, Kamemoto K. Analysis of Interior Airflow in a Full-Scale Passenger-Compartment Model Using a Laser-Light-Sheet Method 1992.

[57] Ružić D. Numerical simulation of tractor operator thermal loads caused by solar radiation. Пољопривредна Техника / Agric Eng 2014;39:1-8.

[58] Guillaume, Leduc; Françoise, Monchoux; Francoise T. Analysis of human's radiative exchange in a complex enclosure. Mov Therm Comf Stand into 21st Century, Apr 2001, Cumber- L Lodg Winsor, United Kingdom Hal02175360 n.d.

[59] ASHRAE. Handbook of fundamentals. 2001.

[60] McGuffin R, Burke R, Huizenga C, Zhang H, Vlahinos A. Human thermal comfort model and manikin 2002.

[61] Jones BW. Capabilities and limitations of thermal models for use in thermal comfort standards. Energy Build., vol. 34, 2002, p. 6539. 7788(02)00016-6. https://doi.org/10.1016/S0378-

[62] GAGGE AP, STOLWIJK JAJ, NISHI Y. Effective temperature scale based on a simple model of human physiological regulatory response. ASHRAE Trans 1971;77:247-63.

[63] Article O. Evaluation Method of Thermal Comfort in a Vehicle with a Dispersed. CiNiiAcJp 2003;6:77-91.

[64] Tuohy P, Roaf S, Nicol F, Humphreys M, Boerstra A. Twenty first century standards for thermal comfort: fostering low carbon building design and operation. Archit Sci Rev 2010;53:78-86.

https://doi.org/10.3763/asre.2009.0112.

[65] Kilic M, Akyol SM. Experimental investigation of thermal comfort and air quality in an automobile cabin during the cooling period. Heat Mass Transf Und Stoffuebertragung 2012;48:1375-84.

https://doi.org/10.1007/S00231-012-0988-8.

[66] Taniguchi Y. Simulation Models for Predicting Car Occupants Thermal Comfort. R\&D Rev Toyota CRDL 2001;36:36-7.

[67] Taniguchi Y, Aoki H, Fujikake K, Tanaka H, Kitada M. Study on car air conditioning system controlled by car occupants' skin temperaturesPart 1: Research on a method of quantitative evaluation of car occupants' thermal 1992.

[68] Wyon DP. Use of thermal manikins in environmental ergonomics. Scand J Work Environ Heal 1989;15:84-94.

[69] Han T, Huang L. A model for relating a thermal comfort scale to EHT comfort index 2004.

[70] Walgama C, Fackrell S, Karimi M, Fartaj A, Rankin GW. Passenger Thermal Comfort in Vehicles A Review: Http://DxDoiOrg/101243/09544070D00705 2006;220:543-62.
https://doi.org/10.1243/09544070D00705.

[71] Rugh JP, Farrington RB, Bharathan D, Vlahinos A, Burke R, Huizenga C, et al. Predicting human thermal comfort in a transient nonuniform thermal environment. Eur J Appl Physiol 2004 926 2004;92:721-7. https://doi.org/10.1007/S00421-004-1125-2.

[72] Nilsson HO, Arbetslivsinstitutet. Comfort climate evaluation with thermal manikin methods and computer simulation models 2004:202.

[73] Nilsson HO, Holmér I. Foreword. Proc Third Int Meet Therm Manikin Test 3IMM 1997.

[74] Ratts EB, Brown JS. An experimental analysis of cycling in an automotive air conditioning system. Appl Therm Eng 2000;20:1039-58. https://doi.org/10.1016/S1359-4311(99)00080-0.

[75] Murakami S, Kato S, Zeng J. Flow and temperature fields around human body with various room air distribution, Part 1 - CFD study on computational thermal manikin. ASHRAE Trans., vol. 103, 1997, p. 3-15.

[76] Matsunaga K, Sudou F, Tanabe SI. Evaluation of comfort of thermal environment in vehicle occupant compartment. JSAE Rev 1997;18:745. 4304(96)00057-4.

[77] Marcos D, Pino FJ, Bordons C, Guerra JJ. The development and validation of a thermal model for the cabin of a vehicle. Appl Therm Eng 2014;66:646-56.

https://doi.org/10.1016/j.applthermaleng.2014.0 2.054 .

[78] Khayyam H, Kouzani AZ, Hu EJ, Nahavandi S. Coordinated energy management of vehicle air conditioning system. Appl. Therm. Eng., vol. 31, 2011, p. 750-64. https://doi.org/10.1016/j.applthermaleng.2010.1 0.022 .

[79] Fayazbakhsh MA, Bahrami M. Comprehensive modeling of vehicle air conditioning loads using heat balance method. SAE Tech. Pap., vol. 2, 2013. https://doi.org/10.4271/2013-01-1507.

[80] Wang H, Xiang L. Numerical simulation of air conditioning vehicle using computational fluid dynamics. Asia-Pacific Power Energy Eng. Conf. APPEEC, 2009. https://doi.org/10.1109/APPEEC.2009.4918533. 